\title{
PENGARUH GAYA KEPEMIMPINAN TRANSFORMASIONAL, MOTIVASI KERJA, DAN BUDAYA ORGANISASI TERHADAP KINERJA KARYAWAN (Studi Pada PT. BPR Arta Utama Pekalongan)
}

\author{
Robertus Gita*, Ahyar Yuniawan ${ }^{1}$ \\ Email : robertusberto@gmail.com \\ Jurusan Manajemen Fakultas Ekonomika dan Bisnis Universitas Diponegoro \\ Jl. Prof. Soedharto SH Tembalang, Semarang 50239, Phone: +622476486851
}

\begin{abstract}
The purpose of this research is to analyze further the effect of transformational leadership style, employee motivation, and organizational culture on employee performance. In this study, the researcher uses of transformational leadership style, work motivation, and organizational culture as an independent variables and employee performance as the dependent variable.

Methods of data collection in the research that is used is a questionnaire with a sample of 57 permanent employees of PT. BPR Arta Utama Pekalongan (consisting of a central office and four branch offices), in which the research is using a sample of census or using the entire population of employees of PT. BPR Arta Utama. Methods of data analysis used in this research is multiple linear regression analysis.

Based on the multiple linear regression that is performed to produce transformational leadership style, it has a positive and significant impacts on employee performance. Meanwhile, work motivation and organizational culture do not affect the performance of employee.
\end{abstract}

Keywords $\quad$ : Transformational leadership style, work motivation, organizational culture, and employee performance.

\section{PENDAHULUAN}

Di era modern ini banyak perusahaan yang berlomba - lomba untuk menjadi perusahaan yang unggul dalam persaingan. Kemajuan teknologi dan persaingan yang ketat di dalam era globalisasi membuat perusahaan akan selalu melakukan adaptasi terhadap perubahan - perubahan yang terjadi pada lingkungan bisnis. Untuk merespon hal tersebut, maka perusahaan - perusahaan menjadikan sumber daya manusia yang dimilikinya sebagai fokus utama mereka. Hal ini dikarenakan sumber daya manusia merupakan "jantung" dari sebuah perusahaan dalam proses pencapaian tujuan perusahaan. Apabila sumber daya manusia yang dimiliki menghasilkan kinerja yang diharapkan sesuai dengan ekspektasi perusahaan, maka akan membuat perusahaan semakin mudah mencapai tujuan mereka. Berhasil atau tidaknya perusahaan dalam memenangkan kompetisi dapat dilihat dari keberlangsungan hidup perusahaan itu sendiri. Dengan melihat hal tersebut dapat diketahui bahwa perusahaan memiliki strategi yang baik di dalam beradaptasi dengan lingkungan sekitar mereka. Tidak hanya memiliki strategi yang baik saja melainkan untuk mendukung strategi tersebut dibutuhan sumber daya manusia yang berkualitas guna mendukung strategi mereka. Sumber daya manusia atau karyawan yang berkualitas akan dapat menempatkan perusahaan pada jalur persaingan atau bahkan dapat menjadi leader dalam persaingan.

Kualitas sdm di dalam perusahaan harus terus dikembangkan oleh perusahaan yang mana disesuaikan dengan perkembangan zaman saat ini. Dengan begitu para karyawan dapat melaksanakan pekerjaan secara profesional, bertanggung jawab, serta memiliki attitude yang baik guna dapat membantu perusahaan di dalam memenuhi kebutuhan konsumen yang semakin 
kompleks dalam era globalisasi ini. Kinerja adalah hasil dari suatu pekerjaan yang dilaksanakan, baik yang bersifat fisik/material ataupun non - fisik/non material (Hadari Nawawi, 2005). Maka kualitas kinerja karyawan dapat dilihat dengan adanya penilaian kinerja yang dapat memberikan informasi mengenai kinerja karyawan dalam periode tertentu. Penilaian kinerja di dalam prosesnya dapat menggunakan dimensi pengukuran yang beragam, hal ini dikarenakan kinerja karyawan mengacu pada prestasi seseorang yang mana diukur berdasarkan standar dan kriteria yang diterapkan oleh perusahaan (Nurul et al., 2011). Adapun faktor - faktor yang dapat mempengaruhi kinerja karyawan menurut Paganda (2014) yaitu, faktor personal, faktor kepemimpinan, faktor tim, faktor sistem, dan faktor kontekstual. Dengan melihat faktor - faktor yang mempengaruhi kinerja karyawan tersebut, penelitian ini menggunakan gaya kepemimpinan transformasional, motivasi kerja, dan budaya organisasi sebagai variabel yang mendukung penelitian kinerja karyawan di PT. BPR Arta Utama Pekalongan.

\section{TELAAH PUSTAKA}

Kinerja

Menurut Fatchur et al. (2011) kinerja adalah hasil kerja yang dapat dicapai oleh seseorang ataupun dalam kelompok dalam suatu organisasi yang sesuai dengan wewenang serta tanggung jawab masing masing. Maka, dapat disimpulkan dari penjelasan di atas, kinerja adalah suatu hasil kerja secara kualitas dan kuantitas yang dicapai seorang karyawan dalam melaksanakan tugasnya sesuai tanggung jawab yang diberikan yang mana sesuai dengan kriteria yang telah ditentukan oleh perusahaan.

\section{Gaya Kepemimpinan Transformasional}

Kepemimpinan merupakan hal yang wajib dimiliki oleh seorang pemimpin. Hal ini dikarenakan kepemimpinan adalah kemampuan yang dimiliki oleh seseorang untuk mempengaruhi orang lain agar dapat bekerja guna mencapai tujuan dan sasaran (Handoko, 2011). Menurut Wicaksono (2014) gaya kepemimpinan adalah pola tingkah laku yang dilakukan dengan mengintegrasikan tujuan organisasi dengan tujuan individu untuk mencapai tujuan yang diinginkan. Seorang pemimpin di dalam memimpin pasti memiliki gaya kepemimpinan yang sesuai dengan situasi dan kondisi karyawan yang dipimpinnya.

Kemudian, menurut Indrayanto et al. (2013) gaya kepemimpinan transformasional merupakan gaya kepemimpinan yang menginspirasi pengikut untuk terlibat, berkomitmen, dan memiliki visi serta tujuan bagi organisasi mereka, mendorong pengikut menjadi inovatif di dalam memecahkan masalah organisasi, dan mendukung pengikut untuk memiliki kompetensi dalam kepemimpinan melalui pembinaan dan pengawasan. Jadi, berdasar penjelasan di atas gaya kepemimpinan memang hal yang penting dimiliki oleh seorang pemimpin di dalam memimpin.

Adapun penelitian - penelitian mengenai hubungan antara gaya kepemimpinan trasnformasional dengan kinerja karyawan yaitu, Cavazotte et al. (2013), Risambessy et al. (2008), dan Maharani et al. (2013) yang menjelaskan adanya pengaruh positif dan signifikan antara gaya kepemimpinan transformasional dengan kinerja karyawan. Sedangkan, Supendy et al. (2012) menghasilkan bahwa kepemimpinan transformasional berpengaruh positif dan tidak signifikan terhadap kinerja karyawan. Dengan demikian, Hipotesis 1 adalah :

\section{H1:GayaKepemimpinanTransformasional berpengaruh positif terhadap Kinerja Karyawan. \\ Motivasi Kerja}

Menurut Muslih (2012) motivasi mempunyai peran sangat penting bagi karyawan atau para pemimpin, karena dengan adanya motivasi yang tinggi akan berdampak pada pekerjaan yang dilakukan dengan bersemangat dimana akan dapat dicapai kinerja yang tinggi dan tentunya akan mendukung tercapainya tujuan yang diinginkan secara efisien dan efektif. Dengan melihat penjelasan di atas maka, dapat disimpulkan bahwa motivasi merupakan dorongan yang berasal dari dalam maupun luar diri seorang individu untuk menghasilkan output guna mencapai tujuan yang ditentukan. Adanya motivasi kerja yang dimiliki oleh karyawan di dalam bekerja akan membuat karyawan dapat menghasilkan kinerja yang sesuai dengan ekspektasi perusahaan guna membantu perusahaan mencapai tujuan mereka. 
Adanya beberapa penelitian mengenai hubungan antara motivasi kerja dan kinerja karyawan yakni, Djoemadi dan Noermijati (2014), Umar (2011), Juliningrum dan Sudiro (2013) yang mana menghasilkan bahwa adanya pengaruh positif dan signifikan antara motivasi kerja terhadap kinerja karyawan. Sedangkan, penelitian yang dilakukan oleh Kurniawan (2012) menghasilkan bahwa adanya pengaruh positif dan tidak signifikan dari motivasi kerja terhadap kinerja karyawan. Dengan demikian, Hipotesis 2 adalah :

\section{H2 : Motivasi Kerja berpengaruh positif terhadap Kinerja Karyawan. \\ Budaya Organisasi}

Menurut Dessler (2007) budaya organisasi merupakan karakteristik nilai, tradisi, dan perilaku perusahaan yang dipunyai oleh karyawan. Menurut Handayani dan Yusrawati (2013) yang menyatakan bahwa kesuksesan dan kinerja seseorang dalam suatu bidang pekerjaan banyak ditentukan oleh kompetensi, profesionalisme, dan komitmen yang dimiliki terhadap bidang yang ditekuninya.
Sesuai dengan budaya organisasi yang merupakan fokus utama di PT. BPR Arta Utama yaitu profesionalisme, maka penelitian ini mempersempit bahasan mengenai budaya organisasi menjadi budaya profesionalisme. Sedangkan, profesionalisme sendiri menurut Riley (2005) adalah standar aspiratif yang tidak hanya seperangkat persyaratan minimum yang dimiliki oleh sebuah perusahaan, dimana terdapat unsur unsur penting seperti kompetensi, integritas, dan layanan.Adanya beberapa penelitian mengenai budaya organisasi terhadap kinerja karyawan, yakni Brahmasari dan Siregar (2008), Shahzad et al. (2013), dan Nurwati et al. (2012), yang menghasilkan bahwa adanya pengaruh positif dan signifikan antara budaya organisasi terhadap kinerja karyawan.

Sedangkan penelitian yang dilakukan oleh Lina (2014) menghasilkan bahwa adanya pengaruh positif dan tidak signifikan dari budaya organisasi terhadap kinerja karyawan.

Dengan demikian, Hipotesis 3 adalah :

\section{H3 : Budaya Organisasi berpengaruh positif terhadap Kinerja Karyawan.}

\section{Gambar 1}

\section{Kerangka Pemikiran Teoritis}

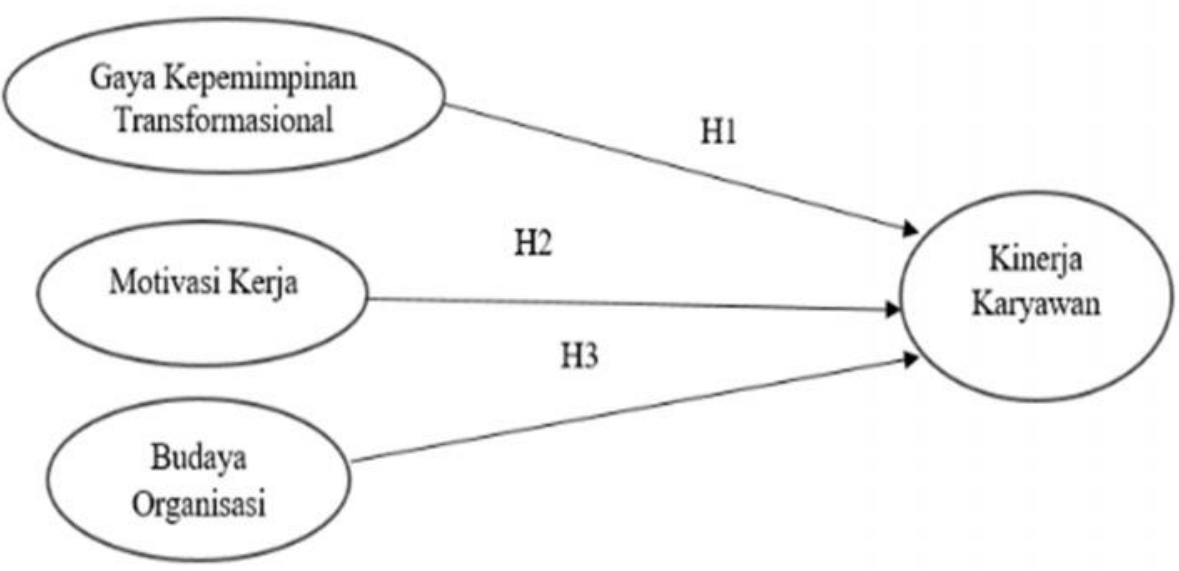

Sumber : Konsep yang dikembangkan dalam penelitian ini, 2016

H1 : Risambessy et al. (2008), Cavazotte et al. (2013), Supendy et al. (2012), dan Maharani et al. (2014).

H2 : Djoemadi dan Noermijati (2014), Umar (2011), Kurniawan (2012) dan Juliningrum dan Sudiro (2013).

H3 : Brahmasari dan Siregar (2008), Sutrisno (2009), Nurwati et al. (2012), dan Lina (2014). 


\section{Gita and Yuniawan ./Jurnal Studi Manajemen \& Organisasi 13 (2016) Desember 161 - 170 http://ejournal.undip.ac.id/index.php/smo}

\section{METODE PENELITIAN}

\section{Jenis dan Sumber Data}

Sumber data yang digunakan dalam penelitian ini adalah data primer, menurut Sugiyono (2010) data primer merupakan sumber data yang langsung dapat memberikan data kepada pengumpul data. Data primer yang didapatkan pada penelitian ini menggunakan kuesioner yang ditujukan untuk 57 orang karyawan sebagai responden penelitian ini PT. BPR Arta Utama Pekalongan.

\section{Populasi dan Sampel}

Menurut Ferdinand (2006) sampel merupakan subset dari populasi, terdiri dari beberapa anggota populasi. Dalam penelitian ini tidak digunakan teknik sampling karena sampel yang diteliti merupakan keseluruhan dari populasi yang ada atau disebut dengan sensus. Mengingat jumlah populasi hanya sebesar 57 karyawan (yang sudah dikurangi dengan 4 orang yang berada di level manajerial) maka tanpa harus mengambil sampel dengan jumlah tertentu penelitian ini mengambil keseluruhan jumlah populasi yang ada untuk dijadikan sampel.

\section{Teknik Analisis}

Berdasarkan hipotesis yang telah dirumuskan dalam penelitian ini, maka alat analisis yang digunakan adalah regresi linier berganda. Selanjutnya uji asumsi klasik yang dilakukan meliputi, uji normalitas, uji multikolinearitas, dan uji heteroskedastisitas.

Guna mengetahui signifikansi pengaruh variabel independen terhadap variabel dependen dilakukan uji hipotesis atau uji t dan uji signifikansi simultan atau uji f. Model regresi yang digunakan adalah :

$$
\mathrm{Y}=\mathrm{a}+\boldsymbol{\beta 1 X 1}+\boldsymbol{\beta 2 X} 2+\beta 3 \mathrm{X} 3+\mathrm{e}
$$

Keterangan :

$\mathrm{Y}=$ Kinerja karyawan

$\mathrm{X} 1=$ Gaya kepemimpinan Transformasional

$\mathrm{X} 2=$ Motivasi kerja

$\mathrm{X} 3=$ Budaya organisasi

A $=$ Nilai intercept $/$ constant

$\beta 1, \beta 2, \beta 3=$ Koefisien regresi variabel bebas

e $\quad=$ Standar eror

\section{Definisi Operasional Variabel}

Gaya kepemimpinan transformasional menunjukkan kepemimpinan yang dapat menginspirasi dan memotivasi para pengikutnya dengan cara yang menarik guna membawa perubahan kea rah yang lebih baik bagi pengikut dan perusahaan. Indikator gaya kepemimpinan transformasional berorientasi kepercayaan pengikut menurut Mas'ud (2004) adalah : Percaya pada pekerjaan, percaya dengan pemimpin, keyakinan dapat menangani masalah, bekerja bukan sekedar mencari uang, percaya pada kemampuan dalam membuat keputusan, mengagumi pemimpin organisasi, menangani situasi yang tidak biasa, pekerjaan bermanfaat bagi masyarakat, percaya keputusan pemimpin, keyakinan mampu mengatasi hambatan dalam pekerjaan.

Motivasi kerja menggambarkan sebuah dorongan atau kemauan keras dari seseorang yang berorientasi pada pencapaian hasil, target, ataupun tujuan tertentu demi memenuhi segala kebutuhannya. Indikator motivasi kerja berorientasi pada teori hirarki kebutuhan Maslow menurut Mas'ud (2004) adalah : Kebutuhan rasa aman, kebutuhan social, kebutuhan pengakuan, kebutuhan otonomi, kebutuhan aktualisasi diri.

Budaya organisasi menunjukkan adanya asumsi yang secara implisit dipegang oleh anggota organisasi yang dijadikan dasar dalam mobilitas organisasi. Dalam PT. BPR Arta Utama budaya yang dikembangkan dan menjadi perhatian utama adalah budaya profesionalisme. Profesionalisme adalah standar aspiratif yang tidak hanya seperangkat persyaratan minimum yang dimiliki oleh sebuah perusahaan, dimana terdapat unsur - unsur penting seperti kompetensi, integritas, dan layanan. Indikator budaya organisasi yang berorientasi pada profesionalisme menurut Mas'ud (2004) adalah : Organisasi berusaha menjadi pionir, dalam organisasi orang mencurahkan seluruh kemampuannya untuk bekerja, dalam organisasi pencapaian hasil lebih penting daripada proses, dalam organisasi setiap orang mengetahui apa tujuan pekerjaan, dalam organisasi setiap orang mengetahui pentingnya pekerjaan, manajer puncak menginginkan pendapat yang berbeda, organisasi ini melampaui organisasi lain dalam teknologi dan metode kerja, orang orang tidak mengeluh menghadapi situasi yang tidak biasa.

Kinerja karyawan tertuju pada hasil kerja yang telah dipenuhi atau dicapai oleh para karyawan yang sesuai dengan standar dan dalam waktu tertentu untuk mencapai tujuan perusahaan. Indikator kinerja 
karyawan yang diambil dalam penelitian ini sudah relevan dengan keadaan atau kegiatan sehari - hari dalam PT. BPR Arta Utama. Indikator kinerja karyawan menurut Mas'ud (2004) adalah : Kualitas kerja, kuantitas kerja, ketepatan karyawan, semangat kerja, efisiensi karyawan.

\section{HASIL ANALISIS}

Uji asumsi klasik yang dilakukan meliputi uji normalitas yang terdiri dari analisis grafik, uji kolmogorov - smirnov dan saphiro - wilk, dan uji skewness - kurtosis yang menunjukkan bahwa data dalam penelitian ini berdistribusi dengan normal. Sedangkan, uji multikolinearitas yang dilakukan tidak adanya indikasi multikolinearitas dengan nilai VIF yang paling tinggi sebesar 1.063.

Uji heteroskedastisitas yang dilakukan juga tidak menunjukkan indikasi terjadi heteroskedastisitas yang mana pada grafik scatterplot titik - tik menyebar secara acak tersebar baik di atas maupun di bawah angka 0 dan sumbu Y.

Dengan serangkaian uji asumsi klasik yang telah dilakukan dalam penelitian ini menunjukkan bahwa model regresi telah memenuhi kelayakan model regresi yang diisyaratkan. Pengujian regresi linier berganda yang dilakukan menghasilkan model regresi linier sebagai berikut :

$$
\mathrm{Y}=0,720 \mathrm{X}_{1}+0,165 \mathrm{X}_{2}+0,151 \mathrm{X}_{3}
$$

\section{Uji Hipotesis H1}

Berdasarkan hasil dari penelitian ini, analisis uji $t$ menunjukkan koefisien regresi pengaruh variabel gaya kepemimpinan transformasional terhadap kinerja karyawan sebesar 0,726. Nilai koefisiensi regresi tersebut menunjukkan bahwa penggunaan gaya kepemimpinan transformasional di dalam memimpin PT. BPR Arta Utama adalah cara yang tepat guna meningkatkan kinerja karyawan. Kemudian uji hipotesis yang telah dilakukan menghasilkan nilai thitung sebesar 7,458 dan memiliki signifikansinya sebesar $0,000<0,05$. Maka, dapat dikatakan bahwa $\mathrm{H} 1$ dalam penelitian ini diterima yang mana secara parsial variabel gaya kepemimpinan transformasional berpengaruh positif dan signifikan terhadap kinerja karyawan PT.
BPR Arta Utama. Hasil penelitian yang dilakukan Cavazotte (2013) yang menghasilkan adanya hubungan positif dan signifikan antara gaya kepemimpinan transformasional terhadap kinerja, dimana hasil tersebut sama dengan hasil penelitian ini.

Dengan hasil penelitian tersebut gaya kepemimpinan transformasional dapat mempengaruhi karyawan ke arah yang lebih baik, yang mana sesuai dengan Gadot (2006) yang menyatakan bahwa gaya kepemimpinan transformasional memiliki efek positif pada sikap karyawan, pekerjaan karyawan, lingkungan kerja karyawan, dan pada akhirnya mempengaruhi kinerja karyawan. Dengan menggunakan gaya kepemimpinan yang dapat membawa perusahaan menuju ke arah yang lebih baik dapat berdampak baik pula terhadap kinerja karyawan dan perusahaan, seperti halnya gaya kepemimpinan transformasional ini.

\section{Uji Hipotesis $\mathbf{H 2}$}

Berdasarkan hasil penelitian ini, analisis uji $\mathrm{t}$ menunjukkan bahwa koefisien regresi pengaruh variabel motivasi kerja terhadap kinerja karyawan sebesar 0,165. Nilai koefisien regresi tersebut menunjukkan bahwa motivasi kerja dari para karyawan PT. BPR Arta Utama perlu ditingkatkan lagi guna dapat meningkatkan kinerja mereka. Kemudian uji hipotesis yang telah dilakukan menghasilkan nilai thitung sebesar 1,757 dan memiliki signifikansi sebesar 0,085 >0,05. Maka, dapat dikatakan bahwa $\mathrm{H} 2$ dalam penelitian ini ditolak, karena motivasi kerja tidak berpengaruh terhadap kinerja karyawan PT. BPR Arta Utama. Hasil penelitian ini sesuai dengan penelitian yang dilakukan Kurniawan (2012) yang menghasilkan bahwa motivasi kerja tidak berpengaruh terhadap kinerja karyawan.

Dari hasil penelitian ini dapat diketahui bahwa motivasi kerja belum cukup membuat karyawan memiliki kinerja yang maksimal di dalam bekerja. Hal ini sesuai dengan hasil penelitian yang dilakukan oleh Kurniawan (2012) bahwa karyawan di dalam bekerja untuk mencapai target yang ditentukan, hanya melakukan pekerjaan karena takut kehilangan pekerjaannya saja. Sehingga terjadi banyak penyimpangan penyimpangan yang dilakukan para karyawan di dalam bekerja yang dapat 


\section{Gita and Yuniawan ./Jurnal Studi Manajemen \& Organisasi 13 (2016) Desember 161 - 170 http://ejournal.undip.ac.id/index.php/smo}

membuat kinerja mereka tidak bagus bagi perusahaan.

Dalam melaksanakan proses penelitian ini, para karyawan PT. BPR Arta Utama di dalam menggambarkan motivasi kerja yang dimiliki dengan mengisi kuesioner yang digunakan dalam penelitian ini dapat terlihat pada angka indeks variabel motivasi kerja dimana tergolong ke dalam kategori tinggi, terdapat peluang bahwa karyawan hanya mengisi karena didasari rasa takut apabila mereka memiliki motivasi kerja yang buruk dan diketahui oleh pimpinan mereka akan dapat membuat pimpinan mereka mengetahui motivasi kerja yang dimiliki para karyawannya yang mungkin dapat berakibat karyawan akan kehilangan pekerjaan mereka, sehingga peluang hal tersebut terjadi sangatlah mungkin di dalam karyawan mengisi kuesioner penelitian ini. Dengan adanya penjelasan mengenai hal - hal apa sajakah yang mempengaruhi motivasi kerja tidak berpengaruh terhadap kinerja karyawan di PT. BPR Arta Utama di atas, dapat dsimpulkan bahwa tidak berpengaruhnya motivasi kerja terhadap kinerja karyawan dipengaruhi oleh berbagai hal yang membuat karyawan tidak memiliki motivasi kerja yang baik guna meningkatkan kinerja mereka.

\section{Uji Hipotesis H3}

Berdasarkan hasil penelitian ini, analisis uji t menunjukkan koefisien regresi pengaruh variabel motivasi kerja terhadap kinerja karyawan sebesar 0,151. Nilai koefisiensi regresi tersebut menunjukkan bahwa budaya organisasi yang diciptakan PT. BPR Arta Utama masih belum cukup baik untuk meningkatkan kinerja karyawannya. Kemudian uji hipotesis yang telah dilakukan menghasilkan nilai $t_{\text {hitung }}$ sebesar 1,568 dan memiliki signifikansi sebesar $0,123>0,05$. Maka, dapat disimpulkan bahwa H3 dalam penelitian ini ditolak, karena budaya organisasi (profesionalisme) tidak berpengaruh terhadap kinerja karyawan PT. BPR Arta Utama. Hasil penelitian ini sesuai dengan penelitian yang dilakukan Cahyasumirat (2006) yang menghasilkan profesionalisme tidak berpengaruh terhadap kinerja karyawan.

Dari hasil penelitian ini dapat diketahui bahwa budaya organisasi (profesionalisme) belum cukup membuat karyawan memiliki kinerja yang maksimal di dalam bekerja. Hasil penelitian ini sesuai dengan hasil penelitian yang dilakukan oleh Cahyasumirat (2006) yang mana tingkat profesionalisme seseorang tidak berpengaruh terhadap kinerja mereka, profesionalisme dapat ditingkatkan dengan melalui program pendidikan berkelanjutan sehingga, karyawan dapat mendapatkan wawasan dan pengetahuan yang dapat meningkatkan kinerja mereka di dalam bekerja. Dengan demikian, hasil penelitian ini yang menghasilkan profesionalisme tidak berpengaruh terhadap kinerja karyawan dipengaruhi banyak hal. Adanya program pelatihan atau pendidikan berkelanjutan dapat meningkatkan profesionalisme karyawan di dalam bekerja, karena karyawan mendapatkan pengetahuan dan wawasan tambahan yang dapat membantu mereka mampu menyelesaikan masalah di dalam pekerjaan mereka yang akhirnya dapat memiliki kinerja yang baik.

Dalam melaksanakan proses penelitian ini, para karyawan PT. BPR Arta Utama di dalam menggambarkan budaya organisasi (profesionalisme) yang diterapkan dengan mengisi kuesioner yang digunakan dalam penelitian ini dapat terlihat pada angka indeks variabel budaya organisasi dimana tergolong ke dalam kategori tinggi, terdapat peluang penerapan profesionalisme di PT. BPR Arta Utama bagi para karyawan belum adanya pemberian feedback yang sesuai dengan standar profesionalisme yang telah ditentukan, sehingga karyawan di dalam menerapkan profesionalisme dalam bekerja akan merasa dihargai yang mana dapat membantu karyawan memiliki kinerja yang baik. Sebaliknya, apabila tidak adanya feedback yang sesuai dengan standar profesionalisme yang ditentukan, maka para karyawan yang menerapkan profesionalisme belum dapat memiliki kinerja yang baik bagi perusahaan, karena karyawan tidak merasa dihargai sesuai dengan apa yang telah dilakukan untuk perusahaan yang sesuai dengan standar yang telah ditentukan oleh perusahaan. Dengan adanya penjelasan mengenai hal - hal apa sajakah yang mempengaruhi profesionalisme tidak berpengaruh terhadap kinerja karyawan di PT. BPR Arta Utama di atas, dapat disimpulkan bahwa tidak berpengaruhnya profesionalisme terhadap kinerja karyawan dipengaruhi oleh berbagai hal di sekeliling karyawan di perusahaan yang membuat 
mereka belum cukup mampu untuk meningkatkan kinerja mereka dengan profesionalisme yang dimilikinya dalam bekerja.

\section{KESIMPULAN}

Dari hasil analisis data dan pembahasan yang dilakukan dalam penelitian ini, serta sesuai dengan tujuan penelitian, maka akan disimpulkan hal - hal sebagai berikut :

1. Hasil penelitian ini menunjukkan bahwa penggunaan gaya kepemimpinan transformasional yang semakin baik bagi karyawan akan berpengaruh pada peningkatan kinerja karyawan di PT. BPR Arta Utama. Namun sebaliknya, apabila penggunaan gaya kepemimpinan transformasional yang tidak semestinya akan berdampak pada penurunan kinerja karyawan. Maka, gaya kepemimpinan transformasional diperlukan di dalam memimpin karyawan di PT. BPR Arta Utama guna memiliki tingkat kinerja yang tinggi untuk membantu perusahaan menggapai tujuan mereka.
2. Hasil penelitian ini menunjukkan bahwa karyawan selama ini belum memiliki motivasi kerja yang mampu membuat mereka memiliki kinerja yang baik dalam bekerja di PT. BPR Arta Utama. Maka, karyawan perlu memiliki motivasi kerja yang ditujukan untuk dapat melakukan pekerjaannya dengan rasa senang sehingga dapat memiliki kinerja yang baik bagi PT. BPR Arta Utama guna membantu menggapai tujuan yang telah ditentukan.

3. Hasil penelitian ini menunjukkan bahwa profesionalisme yang diterapkan di PT. BPR Arta Utama belum cukup untuk karyawan memiliki kinerja yang baik dalam bekerja. Maka, perlu diperhatikan kembali mengenai penerapan profesionalisme yang dilakukan PT. BPR Arta Utama untuk para karyawannya dengan hal - hal yang mendukung profesionalisme. Sehingga, penerapan profesionalisme yang dilaksanakan dapat membuat karyawan memiliki kinerja yang baik dari para karyawan PT. BPR Arta Utama.

\section{REFERENSI}

Brahmasari, I. dan Peniel, S. 2008. Pengaruh Budaya Organisasi, Kepemimpinan Situasional, dan Pola Komunikasi terhadap Disiplin Kerja dan Kinerja Karyawan pada PT. Central Proteinaprima Tbk. Jurnal Aplikasi Manajemen. Vol. 7. No. 1. ISSN : 1693 - 5241.

Cahyasumirat, G. 2006. Pengaruh Profesionalisme Dan Komitmen Organisasi Terhadap Kinerja Internal Auditor, Dengan Kepuasan Kerja Sebagai Variabel Intervening (Studi Empiris Pada Internal Auditor PT. Bank ABC). Diambil pada 5 Juni 2016 dari eprints.undip.ac.id.

Cavazotte, F., Valter, M., Jane, B. 2013. "Transformational Leaders and Work Performance: The Mediating Roles of Identification and Self - efficacy." Brazil Administration Review, Rio de Janeiro. Vol. 10. No. 4. Art. 6. pp. 490 - 512. Emerald Insight.

Dessler, G. 2007. Manajemen Sumber Daya Manusia (Jilid 2). Jakarta : PT. Indeks.

Djoemadi, F.R. dan Noermijati. 2014. Pengaruh Karakteristik Pemimpin dan Penghargaan terhadap Motivasi Kerja dan Kinerja Karyawan (Studi pada PT. Visi Karya Agritama). Jurnal Aplikasi Manajemen. Vol. 12. No. 2. ISSN : 1693 - 5241.

Donovan, G. 2012. "A case Study of Employee Self - Actualization in the Workplace." Dissertation Submitted in Partial Fulfillment of the Requirements for the Degree of Doctor of Philosophy Applied Management and Decision Sciences. Walden University. Proquest.

Fatchur, R., Armanu, dan Novita, M. 2011. Pengaruh Pemberdayaan Psikologis dan Komitmen Afektif terhadap Kepuasan Kerja dan Kinerja Pegawai (Studi pada Dinas Tata Kota dan Pengawasan Bangunan Kota Mataram). Jurnal Aplikasi Manajemen. Vol. 10. No. 1. ISSN : $1693-5241$.

Ferdinand, A. 2006. Metode Penelitian Manajemen : Pedoman Penelitian Untuk Penulisan Skripsi, Tesis, Disertasi Ilmu Manajemen. Semarang : Badan Penerbit Universitas Diponegoro.

Gadot, E.V. 2006. "Leadership style, Organizational Politics, and Employees' Performance (An Empirical Examination of Two Competing Models)." Personel Review. Vol. 36, No. 5, pp. 661 - 683. Emerald Insight. 
Ghozali, I. 2001. Aplikasi Analisis Multivariate Dengan Program SPSS. Semarang: BP Universitas Diponegoro. .2006. Aplikasi Analisis Multivariate Dengan Program SPSS. Semarang: BP Universitas Diponegoro.

Handayani, R. dan Yusrawati. 2013. Pengaruh Profesionalisme, Komitmen Organisasi ,dan Budaya Kerja terhadap Kinerja Internal Auditor pada Bank Mandiri Medan. Jurnal Ekonomi, Manajemen, dan Akuntansi. Vol. 21. No. 2. Diambil pada 17 Mei 2016 dari www. Jurnalkiatuir.com.

Handoko, T. Hani. 2011. Manajemen. Yogyakarta: BPFE - Yogyakarta.

Hayati, W.F. 2014. Pengaruh Motivasi, Lingkungan Kerja, dan Fasilitas terhadap Kinerja Karyawan PT. Radio Suara Singgalang Mahimbau (Radio Sushi FM) Padang. Diambil pada tanggal 29 April 2016 dari www. journal. unitas - pdg.ac.id.

Indayati, N., Armanu, T., dan Rofiaty. 2012. Pengaruh Keterlibatan Karyawan, Budaya Organisasi, dan Gaya Kepemimpinan terhadap Komitmen Organisasional dalam Meningkatkan Kinerja Karyawan (Studi pada Universitas Brawijaya). Jurnal Aplikasi Manajemen. Volume 10, No. 2, ISSN: 1693 - 5241.

Indrayanto, A., John, B., Kandy, B., dan Noermijati. 2013. "A case study of transformational leadership and para - police performance in Indonesia." Policing : An International Journal of Police Strategies and Management. Vol. 37. No. 2. pp 373 - 388. Emerald Insight.

Jayanti, A.F. 2015. Analisis Pengaruh Self Actualization dan Kepuasan Kerja terhadap Kinerja Karyawan dengan Organizational Citizenship Behavior (OCB) sebagai Variabel Intervening (Studi Pada PT. Kereta Api Indonesia (Persero) Daop IV Semarang). Diambil pada 16 Februari 2016 dari eprints.undip.ac.id.

Juliningrum, E. dan Achmad, S. 2013. Pengaruh Kompensasi dan Budaya Organisasi terhadap Motivasi Kerja dan Kinerja Pegawai. Jurnal Aplikasi Manajemen. Vol. 11. No. 4. ISSN : $1693-5241$.

Kurniawan, A.W. 2012. Pengaruh Kepemimpinan dan Pengembangan Sumber Daya Manusia terhadap Kepuasan Kerja, Motivasi Kerja, dan Kinerja Karyawan Bank Sulselbar. Jurnal Ekonomi dan Keuangan. Vol. 16. No. 4. ISSN : 1411 - 0393.

Lina, D. 2014. Analisis Pengaruh Kepemimpinan dan Budaya Organisasi terhadap Kinerja Pegawai dengan Sistem Reward sebagai Variabel Moderating. Jurnal Riset Akuntansi dan Bisnis. Vol. 14. No. 1. Diambil pada 29 April 2016 dari jurnal.umsu.ac.id.

Logahan, J.M. dan Sherle, M.A. 2014. Budaya Organisasi dan Keterlibatan Kerja terhadap Komitmen Organisasi pada Kinerja Karyawan pada BTN - Ciputat. Binus Business Review. Vol. 5. No.2. Diambil pada 29 April 2016 dari http://researchdashboard.binus.ac.id/uploads/paper/document/publication/Proceeding/BB R/Vol\%205\%20No\%202\%20November\%202014/12_MN_Jerry.pdf.

Lumbanraja, P. 2008. Pengaruh Karakteristik Individu, Gaya Kepemimpinan, dan Budaya Organisasi terhadap Kepuasan Kerja dan Komitmen Organisasi (Studi pada Pemerintah Daerah di Provinsi Sumatera Utara). Jurnal Aplikasi Manajemen. Vol. 7. No. 2. ISSN : 1693 - 5241.

Lunenburg, F.C. 2011. "Organizational Culture Performance Relationship : Views of Excellence and Theory Z." National Forum of Educational Administration and Supervision Journal. Vol. 29. No. 4. Diambil pada tanggal 12 Maret 2016 dari http://www.nationalforum.com/Electronic\%20Journal\%20Volumes/Lunenburg,\%20Fred $\% 20 \mathrm{C} . \% 20$ Organizational\%20CulturePerformance\%20Relationships\%20NFEASJ\%20V 29\%20N4\%202011.pdf.

Ma'arif, M.S., Anggraini, S., dan Dessy, D. 2013. Faktor - faktor yang Mempengaruhi Kinerja Pegawai : Studi di Perusahaan Daerah Pasar Tohaga Kabupaten Bogor. Jurnal Aplikasi Manajemen. Vol. 11. No. 2. ISSN : 1693 - 5241.

Maharani, V., Eka, A.T., Noermijati. 2013. "Organizational Citizenship Behavior Role in Mediating the Effect of Transformational Leadership, Job Satisfaction on Employee Performance : Studies in PT. Bank Syariah Mandiri Malang East Java." International Journal of Business and Management. Vol. 8. No. 17. ISSN : 1833 - 3850. Diambil pada 
30

April

2016

dari

http://www.ccsenet.org/journal/index.php/ijbm/article/view/27599/17557.

Mamesah, M.M. dan Amiartuti, K. 2009. Pengaruh Gaya Kepemimpinan Transformasional dan Transaksional terhadap Kepuasan kerja dan Dampaknya terhadap Kinerja Karyawan. Jurnal Akuntansi, Manajemen Bisnis, dan Sektor Publik. Vol. 5. No. 3. ISSN : 1829 9857.

Mas'ud, F. 2004. Survai Diagnosis Organisasional (Konsep dan aplikasi). Semarang : BP Universitas Diponegoro.

Mathis, R.L. dan John, H.J. 2011. Human Resource Management (Manajemen Sumber Daya Manusia). 10 ed. Jakarta : Salemba Empat.

Muslih, B. 2012. Analisis Pengaruh Motivasi terhadap Kepuasan kerja dan Kinerja Pegawai di PT. Sang Hyang Seri (Persero) Regional III Malang. Jurnal Aplikasi Manajemen. Vol. 10. No. 4. ISSN : $1693-5241$.

Nafiuddin, Y. 2014. Pengaruh Motivasi Kerja dan Kepemimpinan Transformasional terhadap Kinerja Karyawan Bank Tabungan Negara Cabang Yogyakarta. Diambil pada tanggal 7 Mei 2016 dari http://eprints.uny.ac.id/16789/1/Skripsi Yajid\%20NafiuddinNIM\%2009408141002.pdf.

Nawawi, H. 2005. Manajemen Sumber Daya Manusia (Untuk Bisnis yang Kompetitif). Yogyakarta: Gajah Mada University Press.

Noor, Z.A. 2012. Pengaruh Budaya Organisasi, Komitmen Organisasi, dan Motivasi Kerja terhadap Kepuasan Kerja dan Kinerja Karyawan. Jurnal Ekonomi dan Keuangan. Vol. 16. No. 4. ISSN : $1411-0393$.

Notoatmodjo, S. 2009. Pengembangan Sumber Daya Manusia. Jakarta: Rineka Cipta.

Nurwati, Umar, N., Margono, S., dan Surachman. 2012. Pengaruh Kepemimpinan terhadap Budaya Organisasi, Komitmen Kerja, Perilaku Kerja, dan Kinerja Pegawai (Studi pada Satuan Kerja Perangkat Daerah Propinsi Sulawesi Tenggara). Jurnal Aplikasi Manajemen. Vol. 10. No. 1. ISSN : 1693 - 5241.

Oemar, Y. 2013. Pengaruh Budaya Organisasi, Kemampuan Kerja, dan Komitmen Organisasi terhadap Organizational Citizenship Behavior (OCB) Pegawai pada BAPPEDA Kota Pekanbaru. Jurnal Aplikasi Manajemen. Vol. 11. No. 1. ISSN : 1693 - 5241.

Paganda, B. 2014. Analisis Pengaruh Budaya Organisasi dan Kepemimpinan terhadap Kinerja Dengan Motivasi sebagai Variabel Intervening (Studi pada Karyawan PT. Suri Tani Pemuka). Diambil pada tanggal 20 Maret 2016 dari eprints.undip.ac.id.

Rahmi, S. 2014. Kepemimpinan Transformasional dan Budaya Organisasi (Ilustrasi Di Bidang Pendidikan). Jakarta : Mitra Wacana Media.

Riley, J. 2005. “Aspiring to a Culture of Professionalism.” Computer Weekly, Oct 11 2005, pg. 12.

Risambessy, A., Bambang, S., Armanu, T., Endang, S.A. 2008. Pengaruh Gaya Kepemimpinan

Transformasional, Motivasi, Burnout, terhadap Kepuasan Kerja dan Kinerja Karyawan. Jurnal Aplikasi Manajemen. Vol. 9. No. 3. ISSN : 1693 - 5241.

Robbins, S.P. 2006. Perilaku Organisasi. 10 ed. Jakarta : PT. Indeks Kelompok Gramedia.

Robbins, S.P. dan T.A. Judge. 2015. Perilaku Organisasi. 16 ed. Jakarta : Salemba Empat

Sobirin, A. 2007. Budaya Organisasi (Pengertian, makna, dan aplikasinya dalam kehidupan organisasi). Yogyakarta: UPP STIM YKPN.

Shahzad, F., Zahid, I., dan Muhammad, G. 2013. "Impact of Organizational Culture on

Employees Job Performance : An Empirical Study of Software Houses in Pakistan."

Journal of Business Studies Quarterly. Vol. 5. No. 2. Proquest.

Sugiyono. 2010. Metode Penelitian Bisnis. Bandung : CV Alfabeta.

Sundi, K. 2013. "Effect of Transformational Leadership and Transactional Leadership on Employee Performance of Konawe Education Department at Southeast Sulawesi Province." International Journal of Business and Management Invention. Vol. 2. Issue. 12. pp 50 - 58. Diambil pada 30 April 2016 dari http://www.ijbmi.org/papers/Vol(2)12/Version-1/F021201050058.pdf.

Supendy, R., Margono, S., Eka, A.T., Surachman. 2012. Pengaruh Kepemimpinan terhadap Motivasi dan Kinerja Karyawan serta Implikasinya terhadap Kepuasan Kerja (Studi 
pada Bank Pembangunan Daerah (BPD) Sulawesi Tenggara). Jurnal Aplikasi Manajemen. Vol. 10, No. 2, ISSN : 1693 - 5241.

Sutrisno, H.E. 2009. Pengaruh Budaya Organisasi, Stress Kerja, dan Komitmen terhadap Kinerja Karyawan CV. Bintang Karya Putra di Surabaya. Ekuitas. Vol. 14. No.4. ISSN : 1411 0393.

Taruno, S.C., Armanu, T., Djumilah, Z. Mintarti, R. 2012. Pengaruh Gaya Kepemimpinan terhadap Kinerja Dosen dengan Kepuasan Kerja dan Motivasi Kerja sebagai Mediator (Studi pada Perguruan Tinggi Swasta di Jayapura). Jurnal Aplikasi Manajemen. Vol. 10. No. 3. ISSN : $1693-5241$.

Umar, A. 2011. Pengaruh Upah, Motivasi kerja, dan Kepuasan kerja terhadap Kinerja pekerja pada Industri Manufaktur di Kota Makassar. Jurnal Aplikasi Manajemen. Vol. 10. No. 2. ISSN : $1693-5241$.

Wicaksono, Y.M. 2014. Analisis Pengaruh Gaya Kepemimpinan Transformasional, Motivasi Kerja, dan Komitmen Organisasi terhadap Kinerja Karyawan (Studi pada Pusat Koperasi Unit Desa Provinsi Jawa Timur). Diambil pada tanggal 6 April 2016 dari eprints.undip.ac.id.

Yaghoubipoor, A., Ong, P.T., dan Elsadig, M.A. 2013. "Impact of the relationship between Transformational and Traditional Leadership Styles on Iran's automobile industry Job Satisfaction." World Journal of Entrepreneurship, Management and Sustainable Development. Vol. 9. No. 1. pp. 14 - 27. Emerald Insight. 